\title{
Avaliação do atrito produzido por braquetes cerâmicos e de aço inoxidável, quando combinados com fios de aço inoxidável*
}

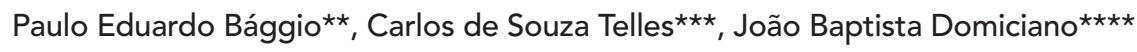

\begin{abstract}
Resumo
Objetivo: no presente trabalho, comparou-se o atrito produzido por braquetes cerâmicos policristalinos e de aço inoxidável, quando combinados com fios de aço inoxidável, durante a execução de mecânica de deslize. Metodologia: com essa finalidade desenvolveram-se um simulador e metodologia apropriados. Resultados e Conclusões: os coeficientes de atrito verificados na combinação braquete cerâmico/fio de aço inoxidável foram superiores aos da combinação braquete de aço inoxidável/fio de aço inoxidável. Assim sendo, a execução de mecânica de deslize é facilitada quando são utilizados braquetes de aço inoxidável com fios de aço inoxidável.
\end{abstract}

Palavras-chave: Atrito. Braquete. Fio.

\section{INTRODUÇÃO}

Os primeiros experimentos sobre atrito datam de aproximadamente 500 anos e foram realizados por Leonardo da Vinci, que registrou, em seu "Código Atlântico", os desenhos de um bloco retangular deslizando sobre uma superfície plana, de diferentes maneiras ${ }^{30}$.

Atrito, segundo Gamow (1976 apud BEDNAR ${ }^{11}$, 1991), é definido como uma força que retarda ou resiste ao movimento relativo de dois objetos em contato, sendo sua direção tangente ao limite comum dessas superfícies.

Apesar de os estudos sobre atrito terem se iniciado há bastante tempo, na literatura ortodôntica, este foi abordado pela primeira vez por Stoner ${ }^{36}$, em 1960, que comentou poder a força aplicada ser dissipada pelo atrito ou aplicação imprópria, sendo difícil controlar e determinar a magnitude que cada dente está recebendo individualmente.

Mais tarde, em 1970, Andreasen e Quevedo ${ }^{1}$ reforçaram o assunto ao comentarem que quando o movimento ortodôntico é realizado pela translação do braquete por um arco contínuo está embutido o atrito que diminui ou interrompe o movimento dentário ótimo e, freqüentemente, faz com que o ortodontista não tenha a correta noção da magnitude de força necessária para movimentar fisiologicamente um dente e ainda vencer o atrito.

Além desses, outros autores ${ }^{7,8,9,20,28,31,40,41}$ realçaram a importância do conhecimento do atrito produzido pelo deslizamento do braquete pelo fio (mecânica de deslize), pois a sua presença pode

* Resumo da tese de doutorado, apresentada à Faculdade de Odontologia da UFRJ.

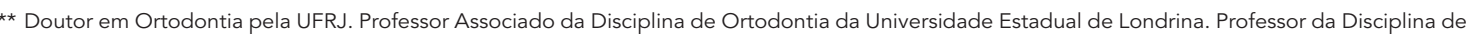
Ortodontia da Universidade Norte do Paraná.

*** Doutor em Ortodontia pela UFRJ. Professor Titular de Ortodontia da Universidade Federal do Rio de Janeiro.

**** Doutor em Física pela USP. Professor Associado do Departamento de Física da Universidade Estadual de Londrina. 
interferir na movimentação dentária, retardandoa ou até anulando-a. Dresher et al. ${ }^{9}$ mostraramse surpresos ao constatarem tão poucos trabalhos científicos publicados sobre esse tema.

A maioria dos braquetes fabricados é de aço inoxidável, devido a suas excelentes propriedades mecânicas, boa resistência à corrosão e baixo custo. Entretanto, procurando-se melhorar o aspecto estético desses braquetes, desenvolveram-se os braquetes cerâmicos, confeccionados de alumina mono ou policristalina, começando-se a questionar a maior quantidade de atrito que parecia ocorrer, quando da sua utilização.

Vários autores $2,5,13,15,18,23,24,26,29,31,32,33,34,35,38,39$ constataram que os braquetes cerâmicos apresentam mais atrito que os de aço inoxidável, quando se utiliza mecânica de deslize. Kusy ${ }^{22}$ acrescentou que os braquetes cerâmicos, exceto pela sua estética, são muito inferiores aos de aço inoxidável e que muito pouco pode ser feito para aperfeiçoá-los.
Tentando explicar o maior atrito dos braquetes cerâmicos, alguns autores ${ }^{12,15,22,25,32}$ atribuíram esse fato à sua maior rugosidade superficial, do que discorda $\mathrm{Kusy}^{22}$, ao comentar que o maior atrito deve-se à sua estrutura química intrínseca.

Por outro lado, Kusy, Whitley e John ${ }^{25}$ não encontraram diferenças significantes nos níveis de atrito entre os braquetes de aço inoxidável e os cerâmicos, comentando ter sido o resultado surpreendente. Bednar et al. ${ }^{3}$ afirmaram que nos braquetes de aço inoxidável ocorre um aumento do atrito à medida que aumenta a dimensão do fio, ocorrendo o inverso com os braquetes cerâmicos e que, de uma maneira geral, os braquetes cerâmicos, produzem menos atrito que os de aço inoxidável.

Assim sendo, o presente trabalho teve por finalidade comparar o atrito produzido por braquetes cerâmicos policristalinos e de aço inoxidável, quando combinados com fios de aço inoxidável, durante a execução de mecânica de deslize.

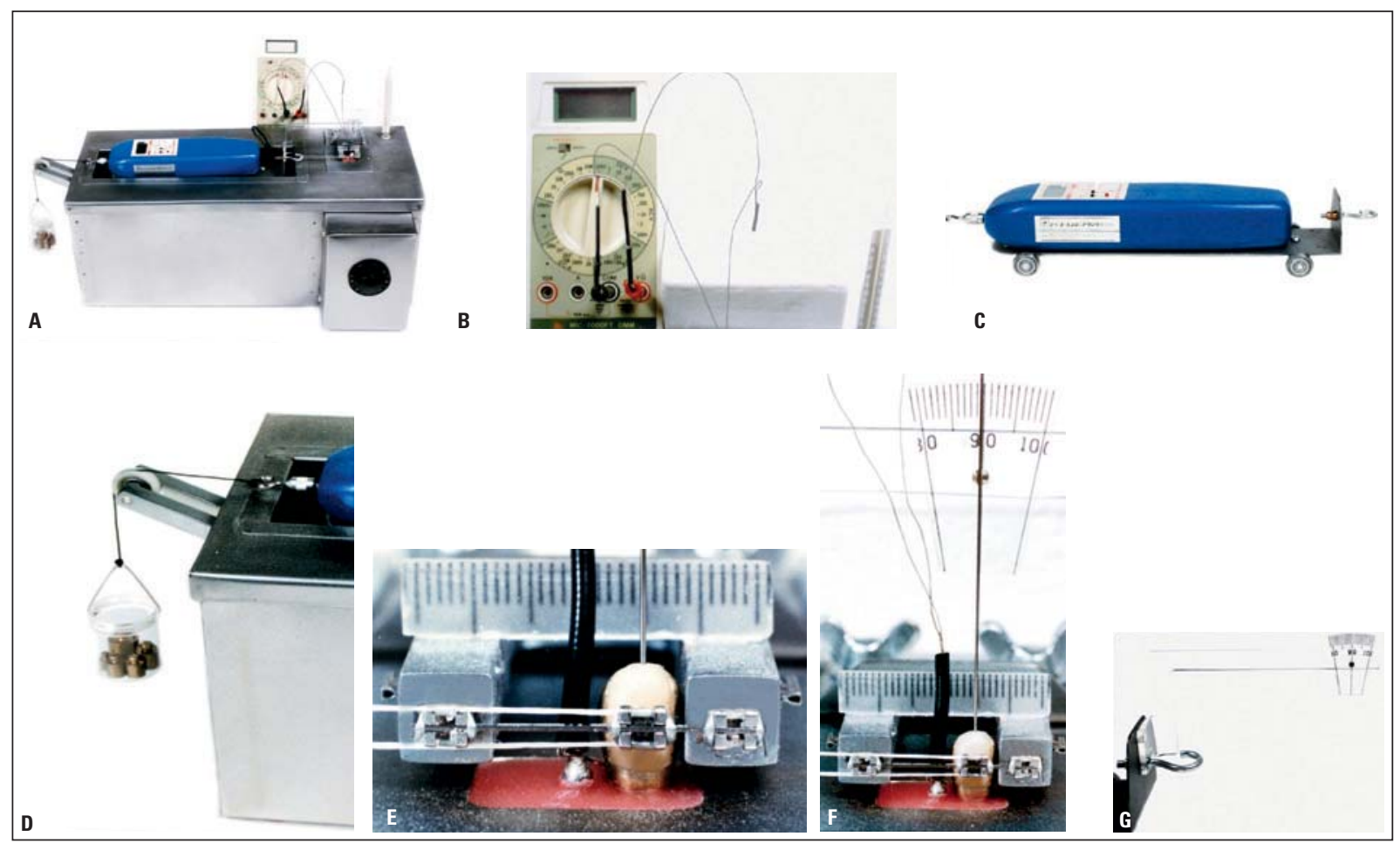

FIGURA 1 - A) Vista frontal do simulador; B) termopar de cobre-constantan para controle da temperatura da cera; C) tensiômetro acoplado ao carrinho com roldanas; D) recipiente para colocação da carga; E) simulação da distalização do canino; F) registro do deslocamento e da angulação do canino; G) conexão do transferidor ao carrinho do tensiômetro. 


\section{MATERIAL E MÉTODOS}

Com o propósito de avaliar in vitro a resistência friccional de braquetes Edgewise standard geminados 0,022 " x 0,030 ", com largura de $3,8 \mathrm{~mm}$, de aço inoxidável (Dentaurum -700-006) e cerâmico policristalino (Dentaurum - 714-0225), combinados com fio de aço inoxidável 0,019" x 0,025" (Standard - Unitek - 251-925), desenvolveu-se um dispositivo que simula a distalização de um canino, quando da extração do primeiro prémolar (Fig. 1A, 2A). Um canino metálico (Fig. 3) foi incluído em cera $\mathrm{n}^{\circ} 7$ (Fig. 2D), aquecido em água a uma temperatura de $58^{\circ} \mathrm{C}$, controlada por um termostato e um termômetro (Fig. 1A). Os experimentos iniciaram somente quando a cera atingiu a temperatura de $48^{\circ} \mathrm{C}$, sendo o registro feito por um termopar de cobre-constantan (Fig. 1A, $1 B, 1 F)$. Um segmento de fio de aço inoxidável foi encaixado passivamente nos braquetes, amarrado com ligadura elástica (Power "O" - Ormco 6400121). O canino foi então distalizado, após a cera atingir a temperatura ideal, por meio de um fio dental (Fig. 1E, 2E) conectado a um carrinho com rodas feitas com rolamentos (Fig. 1C, 2C, 2E), que serviu de suporte para o tensiômetro, cuja ponta ativa era unida a um recipiente através de um fio de nylon que passava por uma roldana (Fig. 1D, 2B). No recipiente, colocou-se a carga e, quando a cera atingia a temperatura ideal, o carrinho era destravado e o deslocamento do dente e o ângulo entre o braquete e o fio registrados visualmente, a cada 30 segundos, empregando-se uma régua milimetrada e um transferidor (Fig. 1F), ambos acoplados ao dispositivo.

Registrou-se também o tempo gasto para o canino atingir a outra extremidade do simulador, que correspondia à face mesial do segundo prémolar. O valor da carga a ser utilizada foi estabelecido em estudo prévio, que consistiu em dois tipos de experimentos. Primeiramente, foram realizados oito deslocamentos do canino na cera, visando a medição da carga mínima necessária para vencer exclusivamente a resistência da cera, resultando num valor médio de $61,2 \pm 3,5$ gramas. Num segundo momento, visando a medição da carga mínima necessária para vencer exclusivamente o atrito estático entre o braquete e o fio, foram realizados deslocamentos do canino,

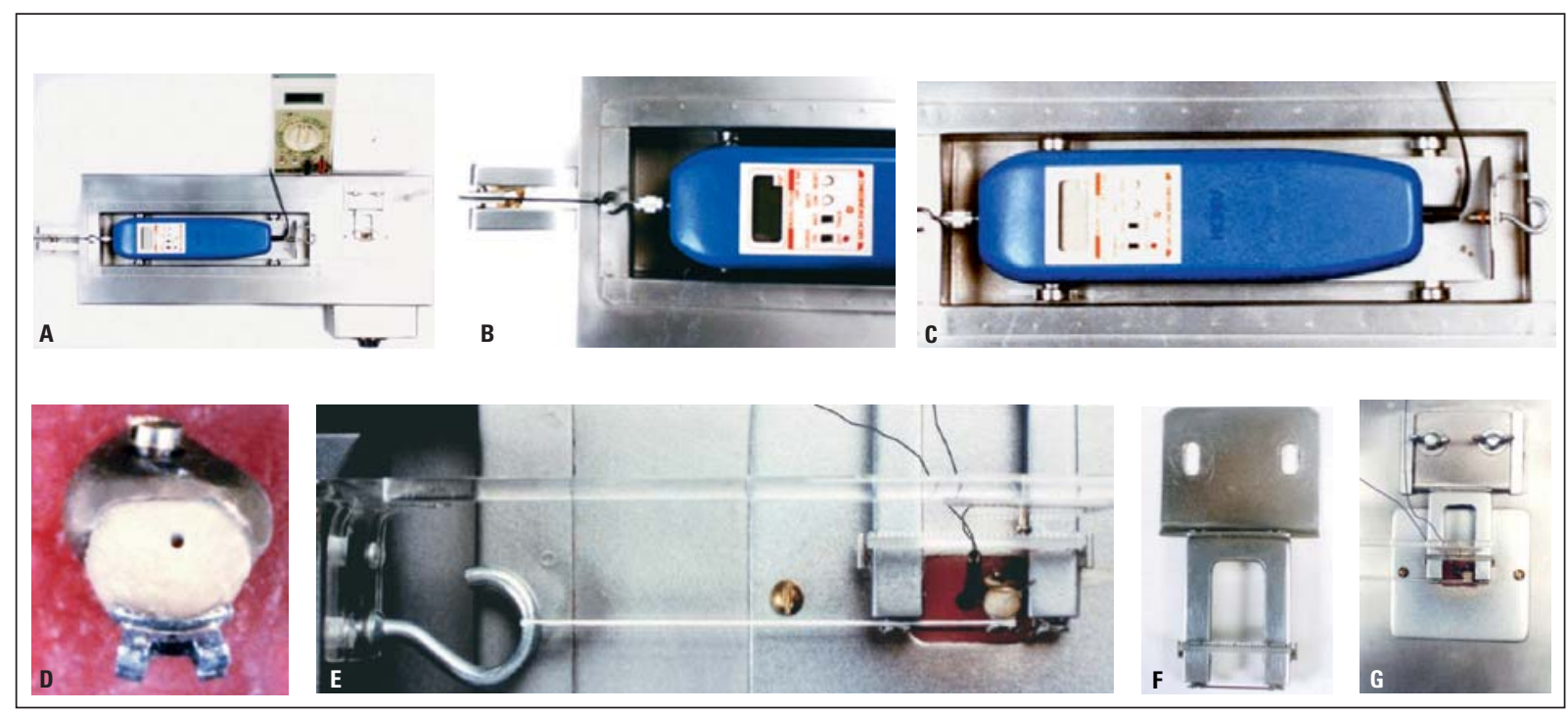

FIGURA 2 - A) Vista superior do simulador; B) roldana do recipiente para a colocação da carga; C) tensiômetro acoplado ao carrinho com roldanas; D) canino incluído na cera; E) conexão com fio dental do braquete do canino ao carrinho do tensiômetro; F) dispositivo removível que simulava o incisivo lateral e 0 segundo pré-molar; G) recipiente removível onde a cera era vertida para incluir o canino. 

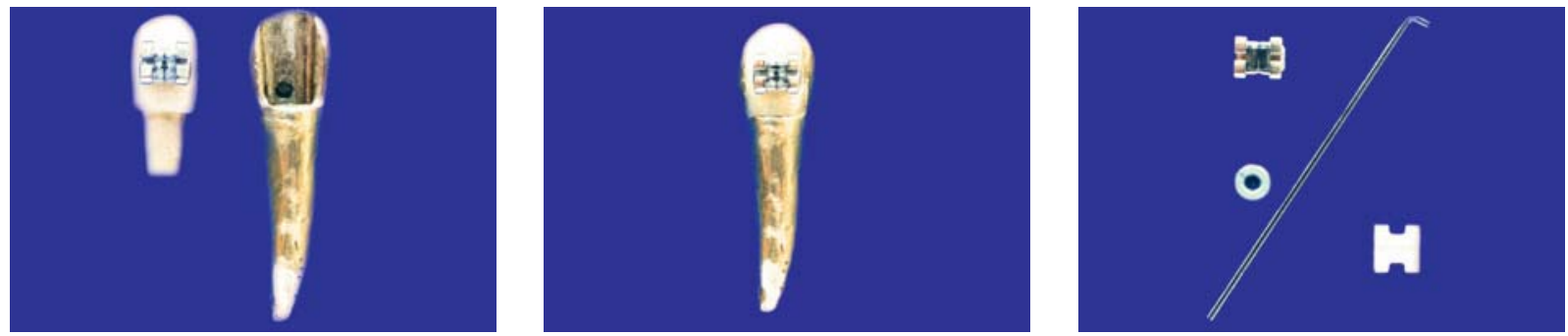

FIGURA 3 - Dente metálico, faceta acrílica, braquetes, fio e ligadura elástica utilizados.

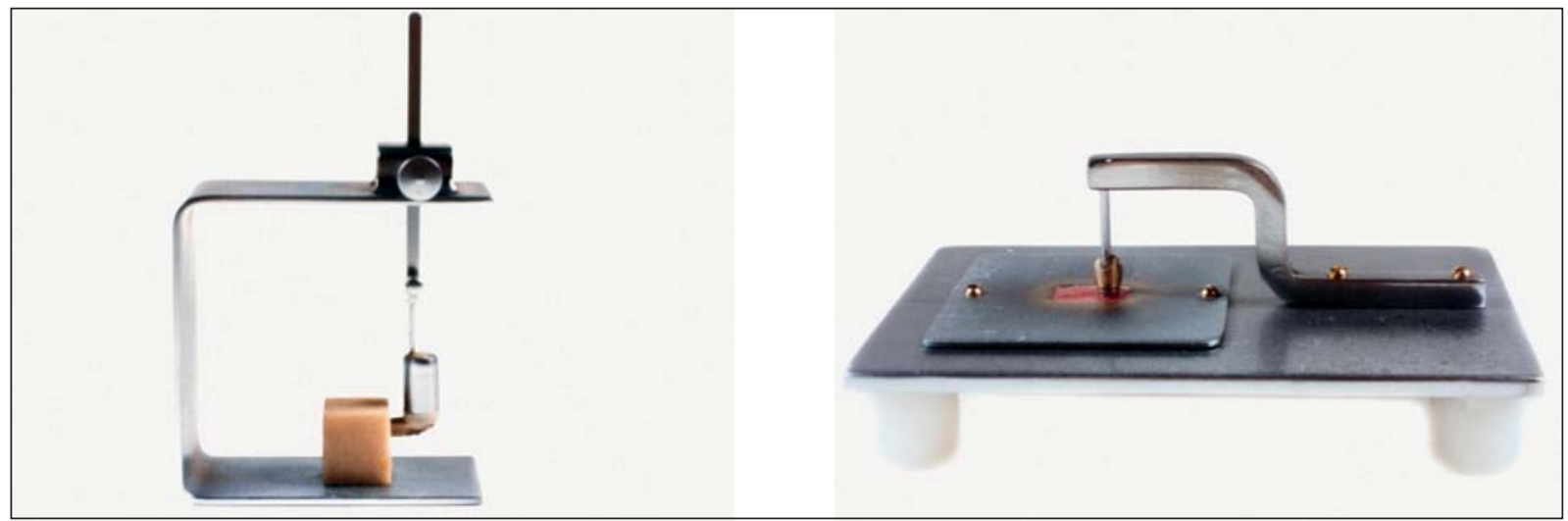

FIGURA 4 - Dispositivos para padronizar a colagem dos braquetes e a montagem do canino no reservatório de cera.

na ausência da cera. A carga mínima necessária para iniciar o movimento foi de 99 gramas, quando da combinação aço/aço, e de 166 gramas, quando da combinação cerâmico/aço. Assim, a carga total mínima para vencer as resistências da cera e do atrito estático da combinação braquete/fio foi de aproximadamente 163 gramas para a combinação aço/aço e 227 gramas para a cerâmico/aço. Para que os deslocamentos ocorressem de maneira ininterrupta, realizaram-se diversos testes com cargas maiores que as citadas cargas totais mínimas. Constatou-se que os valores das cargas que produziam movimentos ininterruptos eram da ordem de 1,5 vez a carga total mínima. Decidiu-se, então, adotar este fator como critério para determinar a carga a ser usada em cada deslocamento. Foram realizados cinco experimentos para cada combinação braquete/fio, com carga de 239 gramas para a combinação aço/aço e de 339 gramas para a cerâmico/aço. Após cada experimento, substituía-se o braquete, fio, ligadura elástica e a cera. Cabe ressaltar que houve uma padronização da colagem dos braquetes nas facetas acrílicas do canino, que eram cambiáveis, bem como do posicionamento do canino na cera (Fig. 4).

Nos experimentos realizados para cada combinação braquete/fio, três forças atuavam sobre o dente: a força aplicada (carga), a força resistiva da cera e a força de atrito entre o braquete e o fio. Ao liberar o sistema, para produzir o movimento do dente, passou a valer a seguinte relação entre as forças que atuam sobre ele:

$$
F_{\text {aplicada }}-F_{\text {res. cera }}-F_{\text {atrito cinético }}=F_{\text {resultante }}
$$

Das três forças que atuam sobre o dente, a força aplicada é a única conhecida antes do início do experimento. A força de resistência da cera e a força de atrito foram determinadas a partir da análise 
do movimento.

A determinação da força de resistência da cera apresentou razoável complexidade, pelo fato de a mesma não se enquadrar em nenhum tipo de fluido de propriedades viscosas conhecidas. Não se encontram teorias já elaboradas sobre forças de resistência viscosa deste tipo de cera em semelhantes deslocamentos. Em textos de Mecânica Geral ou de Mecânica dos Fluidos', 14,27,37 são apresentadas análises de problemas de deslocamentos de objetos em meios fluidos ideais, em casos onde, geralmente, os objetos têm formas geométricas apropriadas, tais como esferas ou cilindros, e têm velocidades muito maiores que aquelas ocorridas nos presentes experimentos. Em tais problemas, as forças de resistência ideais podem ser consideradas como uma função $F_{r e s}(v)$, isto é, uma função da velocidade, do tipo:

$$
F(\mathrm{v})=\beta \mathrm{v}^{n}
$$

onde $\beta$ e $n$ são parâmetros determinados a partir de experimentos apropriados. Em geral, as forças de resistência que se manifestam em fluidos reais são mais complicadas, mas a aproximação de leide-potência da velocidade ( $\left.\mathrm{v}^{n}\right)$ é útil em muitos casos, nos quais a velocidade não apresenta grandes variações, como é o caso nos presentes experimentos. Visto que o valor de $n$ não é previamente conhecido, foi desenvolvido um método para sua medição. Tendo como base a relação (2), foram realizados dez testes de deslocamentos do dente na cera, na ausência do atrito braquete/fio, onde se conhecia cada uma das forças aplicadas e media-se a velocidade média do deslocamento. Com estes valores de $F$ e $v$, foi construído um gráfico e os pontos experimentais foram ajustados por uma função do tipo (2), qual seja,

$$
F(v)=135 v^{0,4}
$$

quando $F$ é considerada em gramas e $v$ em $\mathrm{mm} / \mathrm{min}$, ou

$$
F(v)=1,32 v^{0,4}
$$

quando $F$ é considerada em Newton, pois, para se converter um valor de força dado na unidade "usual" (grama) para a verdadeira unidade de força (Newton), é necessário converter a massa para quilograma e multiplicar pelo fator $\mathrm{g}=9,8 \mathrm{~m} / \mathrm{s}^{2}$. Portanto, para passar da relação (3) para a (4), fez-se $\frac{135}{1000} \times 9,8$

Pelo método exposto, para determinar a força de resistência da cera nos experimentos principais, basta determinar a velocidade dos respectivos deslocamentos e utilizar uma das duas relações (3) ou (4).

Por fim, a força de atrito é determinada como conseqüência da determinação da força resultante. Esta pode ser determinada pela análise do movimento, isto é, pela determinação da forma, como o deslocamento ocorre com o tempo. Para tal, ao se realizarem os movimentos, registram-se os valores de tempo $(\mathrm{t})$ e as respectivas posições do deslocamento do dente (y). Para, com tais valores, construir gráficos que possibilitassem chegar à função $y(t)$. A partir de tal função, é possivel obter a aceleração em função do tempo [a(t)] e, pela segunda lei de Newton, obter a força resultante, pois tal lei estabelece que:

m.a. $=F_{\text {resultante }}$

onde, para o presente caso, $\mathrm{m}$ é a massa do dente. Obtida a força resultante, acha-se a $F_{\text {atrito }}$ através da relação (1).

Uma vez determinada a $F_{\text {atrito }}$, calcula-se o coeficiente de atrito cinético $(\mu)$ entre as superfícies braquete/fio, através da relação

$$
\mu=\frac{F_{\text {at }}}{F_{\mathrm{N} \text { total }}}
$$


onde $F_{\mathrm{N} \text { total }}$ é a força normal total que o fio aplica sobre a ranhura do braquete, como conseqüência da força $\left(F_{\text {elástica }}\right)$ que a ligadura elástica aplica sobre o fio em cada uma das duas extremidades do braquete. Por sua vez, a determinação desta última força baseia-se na lei de Hooke:

$$
F_{\text {elástica }}=\mathrm{k} \cdot \Delta \chi
$$

que relaciona a força elástica e a elongação $(\Delta \chi)$, experimentada pelo elástico, quando este é montado no conjunto braquete/fio. A constante de proporcionalidade $\mathrm{k}$ é chamada constante elástica da ligadura. Visto que o valor de $\mathrm{k}$ não é previamente conhecido, foi desenvolvido um método para sua medição. Foram realizados trinta testes de elongação de elásticos do mesmo tipo e série. Em cada teste usava-se um elástico novo, onde se pendurava um peso de valor conhecido e se media o valor da elongação, determinando-se $\mathrm{k}$ através da relação (7). Adotouse, para cada teste, a carga de 635 gramas, pois constatou-se que, com este valor, a ligadura elástica experimentava elongações da mesma ordem de valor da que ocorria na montagem da mesma na combinação braquete/fio, cujo valor medido foi $\Delta \chi=5,7 \mathrm{~mm}$, para o comprimento inicial do elástico, $\chi_{0}=6,28 \mathrm{~mm}$. Nos trinta testes, a elongação média foi de $6,34 \mathrm{~mm}$ e, então, a partir da relação (7) foi obtido o valor:

$$
\mathrm{k}=100,2 \frac{\text { gramas }}{\mathrm{mm}}
$$

para a constante elástica. Assim, a força normal total que a ligadura elástica aplica sobre o fio é dada por:

$$
F_{\text {Notal }}=2 \times(100,2 \cdot \Delta \chi)=200,4 \cdot \Delta \chi
$$

onde se multiplicou por dois porque o elástico comprime as duas extremidades do braquete. Para calcular o valor da relação (8) basta medir a elongação $\Delta \chi$ da ligadura, ao ser montada no conjunto braquete/fio.

\section{RESULTADOS}

Verificou-se que, em todos os experimentos, a posição (y) do dente, em relação à origem, seguia, com o tempo $(\mathrm{t})$, um comportamento do tipo mostrado no gráfico 1 , o qual se refere a um dos testes da combinação aço/aço.

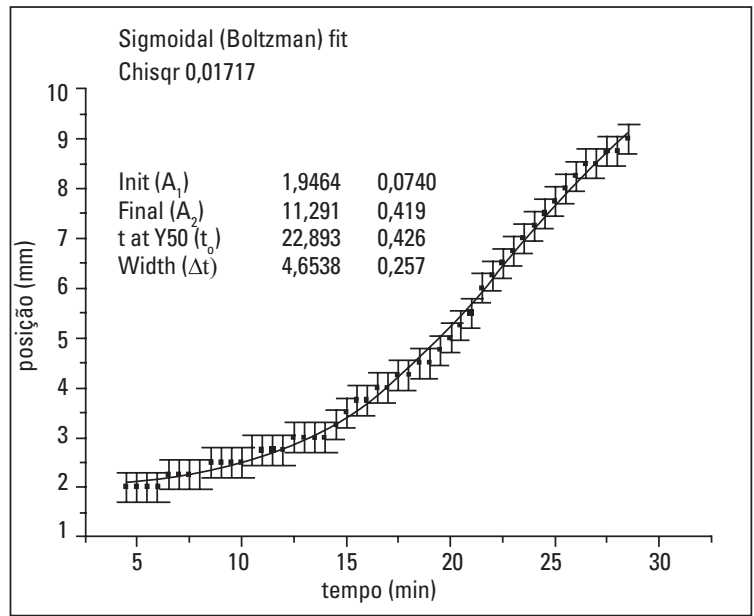

GRÁFICO 1 - Valores da posição do dente em função do tempo num deslocamento com a combinação aço/aço; as barras de incerteza corroboram a verossimilhança do ajuste de uma função sigmóide ao conjunto de pontos.

Verificou-se que uma função sigmóide do tipo mostrado na relação (9) ajusta-se muito bem ao conjunto de pontos experimentais $(\mathrm{t} ; \mathrm{y})$, no trecho $\mathrm{y}=2 \mathrm{~mm}$ a $\mathrm{y}=9 \mathrm{~mm}$ :

$$
y(t)=A_{2}+\frac{A_{1}-A_{2}}{1+e^{\frac{t-t_{0}}{\Delta t}}}
$$

Os parâmetros $A_{1}, A_{2}, t_{0}$ e $\Delta t$ relacionam-se com a conformação da curva, isto é, assumem valores característicos para cada curva.

Os parâmetros impressos no script junto do gráfico significam que, para o movimento representa- 
do, a função dada em (9) pode ser escrita como:

$y(t)=11,291-\frac{1,9464-11,291}{1+e^{\frac{t-22,893}{4,6538}}}$

ou ainda,

$y(t)=11,291+\frac{9,3446}{1+e^{\frac{t-22,893}{4,6538}}}$

Então, a relação (9) é a função y(t) genérica, válida para todos os deslocamentos estudados; a relação (11) é a função y(t) para um teste particular.

O gráfico 2 apresenta as posições em função do tempo num deslocamento com a combinação cerâmico/aço, tomado como exemplo.

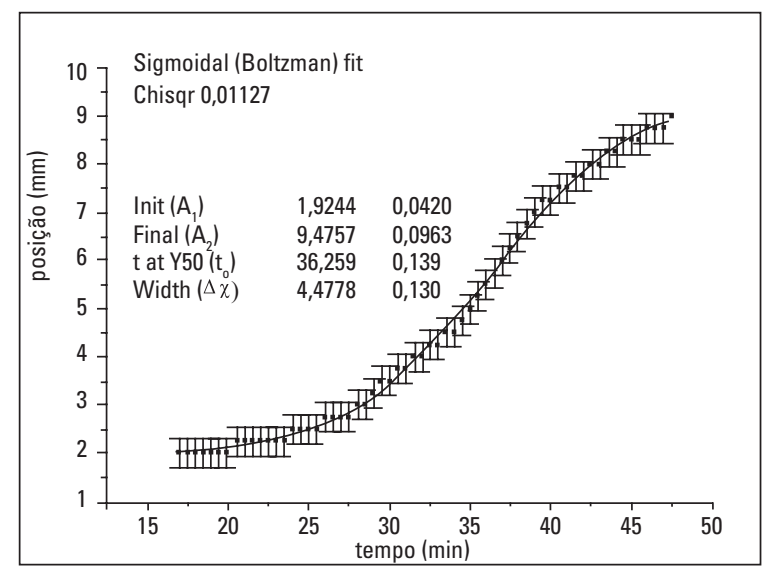

GRÁFICO 2 - Valores da posição do dente em função do tempo num deslocamento com a combinação cerâmico/aço; as barras de incerteza corroboram a verossimilhança do ajuste de uma função sigmóide ao conjunto de pontos.

Um resultado imediato que se pode obter dos gráficos anteriores é a força de resistência da cera nos referidos deslocamentos. Para isso, calculou-se, no percurso, a velocidade média do movimento. No primeiro deslocamento, tomado como exem- plo, o percurso de $7 \mathrm{~mm}$ foi realizado em 24 minutos, resultando em:

$$
\overline{\mathrm{V}}=\frac{7 \mathrm{~mm}}{24 \mathrm{~min}} \cong 0,29 \mathrm{~mm} / \mathrm{min}
$$

Usando a relação (4) ou (3) obtém-se $F_{\text {res cera }}=0,80 \mathrm{~N}$, equivalente a $82 \mathrm{~g}$.

A obtenção da $F_{\text {resultante' }}$, partir da relação (5), exige que se determine a aceleração do dente durante cada percurso total de 2 a $9 \mathrm{~mm}$. Em princípio, previa-se fazer isso através de derivação numérica de segunda ordem, de cada uma das funções particulares do tipo (11), por um software apropriado. Entretanto, este procedimento mostrou-se impraticável porque, através dele, ocorre grande propagação de flutuações para a função derivada de segunda ordem, o que inviabilizou a análise da força resultante, ponto-a-ponto, ou seja, instante a instante do deslocamento. Inúmeros cálculos, realizados para diversos pontos e trechos do deslocamento, mostraram que o valor da força resultante era desprezível em comparação com os valores $d a$ força aplicada (carga) e da força resistiva da cera. Além disso, mostraram que o valor da força resultante permanecia praticamente o mesmo ao longo do deslocamento. Apesar da importância destas informações parciais, não se conseguiu, com este método, a obtenção de uma função $F_{\text {resultante }}(t)$ que fornecesse seu valor a cada instante e possibilitasse, também, a obtenção da $F_{\text {atrito }}(t)$.

Mediante a impossibilidade de se conhecer a força resultante como função do tempo, buscouse conhecê-la como função da posição. Para tanto, determinou-se a função aceleração $a(t)$, genérica, através da derivação analítica de segunda ordem da função $y(t)$ dada em (9). Conhecendo-se, então, as duas funções genéricas, $y(t)$ e a $(t)$, foi possível determinar a função genérica a(y), ou seja, a aceleração em função da posição. Daí, foi determinada a função $F_{r e s}(y)=m \cdot a(y)$, isto é, a for- 
ça resultante como função da posição y ao longo de cada deslocamento. Esta expressão é a própria relação (5), escrita, agora, de modo a permitir o cálculo do trabalho mecânico resultante, o que representa enorme vantagem na análise dos dados experimentais. $\mathrm{O}$ conhecimento da maneira como a força resultante varia com a posição ao longo do deslocamento possibilitou calcular o trabalho mecânico por ela realizado $\left(W_{\text {Fresultante }}\right)$ em cada deslocamento, através da integração:

$$
W_{\text {Fresultante }}=\int_{\mathrm{y}_{0}}^{\mathrm{y}} F_{\mathrm{res}}(\mathrm{y}) \cdot d y
$$

onde os extremos $y_{0}$ e y são definidos pelo trecho do percurso que se deseja analisar.

A grande vantagem de se poder calcular o valor do trabalho mecânico em cada deslocamento é que a grandeza física trabalho engloba os conceitos de força e deslocamento, isto é, deixa-se de pensar e analisar a força ponto-a-ponto e passa-se a analisá-la conjuntamente com o deslocamento produzido, interessando seus efeitos finais. Isso possibilita, ainda, calcular o valor da força média durante o deslocamento, ao invés do valor ponto-a-ponto ou instante-a-instante.

Calcularam-se, também, os trabalhos da força aplicada $\left(W_{F a p l}\right)$ e da força resistiva da cera $\left(W_{\text {Fres.cera }}\right)$. Em virtude de tais forças serem constantes durante o deslocamento, os cálculos dos trabalhos são simples e não necessitam fazer uso da relação (12). Basta fazer:

$W_{\text {Fapl }}=\mathrm{F}_{\text {apl }} . \Delta \mathrm{y}$ e $W_{\bar{F} \text { res.cera }}=\overline{\mathrm{F}}_{\text {res.cera }} . \Delta \mathrm{y}$

Os valores de $W_{\text {Fresultante }}$ da ordem de $10^{-12} \mathrm{~J}$, mostraram-se desprezíveis em relação aos valores de $W_{\text {Fapl }}$ ou de $W_{\text {Fres.cera }}$ ambos da ordem de $10^{-2} \mathrm{~J}$. Significa que, em média, a força resultante pode ser considerada desprezível, quando comparada com as forças envolvidas no deslocamento ou, ain-

da, que se pode considerar $F_{\text {resultante }}=0$. Com isso, a relação (1) pode ser reescrita como:

$F_{\text {aplicada }}-F_{\text {res.cera }}-F_{\text {atrito cinético }}=0$

ou

$F_{\text {aplicada }}-F_{\text {res.cera }}=F_{\text {atrito cinético }}$

A validade da relação (14), nos deslocamentos estudados, tem o significado físico de que eles ocorreram em situações quasi-estáticas, isto é, em situações próximas do equilíbrio, ou ainda, próximas de movimentos uniformes com velocidades muito pequenas. Além disso, o método do cálculo do trabalho mecânico é equivalente a levar em conta o efeito médio das forças em todo o deslocamento e não o efeito ponto-a-ponto, ou instante a instante. Assim, foi possível calcular os valores médios das forças de atrito cinético, durante o deslocamento do dente, para as combinações aço/aço e cerâmico/aço. Os valores medidos constam na tabela 1 , juntamente com os valores de diversas grandezas relevantes, relativas aos pares aço/aço e cerâmico/aço. Como exemplo, o valor de $F_{\text {atrito }}$ para o primeiro teste do par aço/aço foi obtido fazendo-se 239-82=157 gramas, ou 1,54N.

Para o cálculo da força normal, com base na relação (8), mediu-se $\Delta \chi=5,7 \mathrm{~mm}$, resultando o valor $F_{N \text { total }}=200,4.5,7 \cong 1142$ gramas, ou, equivalentemente, 11,2N. Daí, para obter o coeficiente de atrito cinético $(\mu)$, por meio da relação (6), fez-se:

$$
\mu=\frac{157}{1142}=0,137
$$

\section{DISCUSSÃO}

A influência do material com que se fabrica o braquete, no atrito produzido entre ele e o fio, durante a utilização de mecânica de deslize, tem sido questionada por vários autores $2,5,13,15,16,18,19,22,23,24,26,28,32,34,38,39$, que constataram em seus estudos que os braquetes 
Tabela 1 - Valores das forças que atuam sobre o dente e coeficientes de atrito nas combinações aço/aço (A/A) e cerâmico/aço (C/A).

\begin{tabular}{|c|c|c|c|c|c|c|c|c|c|c|}
\hline \multirow{2}{*}{ teste } & \multicolumn{2}{|c|}{ força aplicada (g) } & \multicolumn{2}{|c|}{$\begin{array}{l}\text { força de resistência } \\
\text { média da cera }(\mathbf{g})\end{array}$} & \multicolumn{2}{|c|}{$\begin{array}{l}\text { força de atrito na combi- } \\
\text { nação braquete/fio (g) }\end{array}$} & \multicolumn{2}{|c|}{ força normal (g) } & \multicolumn{2}{|c|}{ coeficiente de atrito $\mu$} \\
\hline & A/A & C/A & $A / A$ & C/A & $A / A$ & C/A & A/A & C/A & $A / A$ & C/A \\
\hline 1 & 239 & 339 & 82 & 75 & 157 & 264 & 1143 & 1143 & 0,137 & 0,231 \\
\hline 2 & 239 & 339 & 89 & 91 & 150 & 248 & 1143 & 1143 & 0,131 & 0,217 \\
\hline 3 & 239 & 339 & 87 & 61 & 152 & 278 & 1143 & 1143 & 0,133 & 0,243 \\
\hline 4 & 239 & 339 & 83 & 83 & 156 & 256 & 1143 & 1143 & 0,137 & 0,224 \\
\hline 5 & 239 & 339 & 86 & 100 & 153 & 229 & 1143 & 1143 & 0,134 & 0,209 \\
\hline média & 239 & 339 & 85 & 82 & 154 & 257 & 1143 & 1143 & $0,134 \pm 0,001$ & $0,225 \pm 0,006$ \\
\hline
\end{tabular}

cerâmicos apresentaram maior atrito que os de aço inoxidável. Os resultados da presente investigação, para os coeficientes de atrito das combinações aço/ aço e cerâmico/aço são, respectivamente, $0,134 \pm$ 0,001 e $0,225 \pm 0,006$ (Tab. 1), que são os valores médios para cada um dos conjuntos de cinco medidas, com seus respectivos desvios-padrão. Portanto, os resultados obtidos confirmam os dos autores anteriormente citados, pois os coeficientes de atrito encontrados na combinação cerâmico/aço foram nitidamente maiores do que os da combinação aço/ aço, em todos os experimentos realizados (Tab. 1). Em contrapartida, outros autores ${ }^{3,17}$ constataram mais atrito nos braquetes de aço inoxidável do que nos cerâmicos. Valores publicados na literatura para o coeficiente de atrito $(\mu)$ são da ordem de 0,5 , para a combinação aço/aço. A diferença entre este e o valor medido pode ser explicada, pelo menos em parte, pelo fato de se ter usado no cálculo de $\mu$ o valor da força normal total que o elástico exerce sobre o fio, pois não existe maneira prática de se medir diretamente a parcela da força normal total que o fio transmite à ranhura do braquete. No entanto, na presente investigação, o valor relativo é mais importante que o absoluto, pois o objetivo principal era comparar os atritos deslizantes de duas combinações braquete/fio.

Procurando explicar a diferença encontrada entre os coeficientes de atrito dos braquetes cerâmicos e dos de aço inoxidável, vários autores $^{3,6,15,17,21,25,26,38}$ comentam ser a superfície dos braquetes de aço inoxidável mais lisa que a dos cerâmicos, tendo Kusy ${ }^{21}$ citado que, de uma maneira geral, a rugosidade superficial dos braquetes cerâmicos é semelhante à de um bloco de concreto, quando comparada com à dos de aço inoxidável, e que sua superfície externa apresenta muitos poros de forma irregular ou poliédrica, com o que concordam Downing et al. ${ }^{6}$ e Tanne et al. ${ }^{38}$

Com base na opinião dos autores e nos resultados do presente trabalho, percebe-se uma relação entre o coeficiente de atrito e a rugosidade dos braquetes de aço inoxidável e cerâmico. Entretanto, Ireland et al. ${ }^{17}$ discordam dessa afirmação, pois encontraram menor coeficiente de atrito nos braquetes cerâmicos, apesar da maior rugosidade de sua superfície. Em contrapartida, Downing et al. ${ }^{6}$ e Spiller et al. ${ }^{35}$ comentam que a composição do braquete teria pouco efeito sobre a resistência friccional.

Outro aspecto a considerar é que, durante o percurso realizado pelo dente, a sua inclinação média foi de $1,5^{\circ}$. Uma parcela desta inclinação é devida à diferença de dimensões do fio $\left(0,019\right.$ " x $\left.0,025^{\prime \prime}\right)$ e a da ranhura do braquete $(0,022$ " x 0,030 "). Para calcular tal parcela, fez-se a subtração $0,022 "-0,019 "=$ 0,003". A partir deste valor, calculou-se o ângulo que essa diferença permitia formar entre o fio e a ranhura, levando-se em conta que é de $3,8 \mathrm{~mm}$ a largura do braquete. Fazendo:

$$
\operatorname{tg} \theta=\frac{0,08}{3,8}=0,02
$$


acha-se $\theta=1,2 \pm 0,2$ grau. Pode-se dizer que, somente quando a inclinação do dente atingia este valor, havia o toque do fio nas bordas da ranhura. A partir desta situação, qualquer aumento da inclinação teria que ser seguido de deformação do fio.

Além disso, poderiam ocorrer, durante o percurso, variações da força normal, provenientes da perda de tensão das ligaduras elásticas; mudanças na direção da linha de ação da força, devidas à inclinação do dente; possíveis diferenças que pudessem existir nas dimensões e superfícies dos braquetes e fios de cada par; diferenças de dilatação térmica entre os diferentes braquetes e fios testados, provenientes da temperatura do simulador; rotações disto-linguais do dente pela não-coincidência da linha de ação da força, tanto vertical como horizontalmente, com o seu centro de resistência; torques vestíbulo-linguais que poderiam ser criados durante o percurso, alterando, assim, a resistência ao deslizamento. Assim sendo, quando se desmembra o valor da força aplicada, para subtrair o valor da resistência da cera, obtém-se a força para vencer o atrito de cada par. Nesse valor, estão embutidos, além do atrito próprio de cada par, o do contato da ligadura elástica com o fio nas extremidades do braquete, atrito este que não se conseguiu mensurar, e as parcelas de contribuição de todas as variáveis anteriormente citadas.

Observa-se, ainda, que o valor de força normal determinado, 11,2N (1.143g), está de acordo com
Edwards et al. ${ }^{10}$ e mostra que, realmente, produzse uma pressão elevada do fio contra a ranhura do braquete. Sabe-se, porém, que os elásticos perdem tensão com o passar do tempo, ocorrendo, de acordo com Dowing et al. ${ }^{6}$, a maior diminuição no intervalo de 5 minutos após a sua colocação. Como nos experimentos realizados, após a colocação da ligadura elástica, aguardava-se um tempo, no mínimo três vezes maior que o mencionado anteriormente, para que a cera atingisse a temperatura ideal, é de se esperar, então, que tenha ocorrido diminuição da força normal antes de se iniciar cada experimento. Além disso, pelo fato de se ter optado por um único modelo de ligadura elástica e ter-se feito um estudo prévio da tensão dessas ligaduras, os valores de força normal seriam similares em todos os experimentos, independentemente da perda de tensão que pudesse ocorrer.

\section{CONCLUSÕES}

1) Os coeficientes de atrito verificados na combinação braquete cerâmico/fio de aço inoxidável foram superiores aos da combinação braquete de aço inoxidável/fio de aço inoxidável.

2) A execução de mecânica de deslize se torna mais eficiente quando utilizados braquetes de aço inoxidável combinados com fios de aço inoxidável.

\title{
Evaluation of friction produced by ceramic and stainless steel brackets, combined with stainless steel wires
}

\begin{abstract}
Aim: to compare the friction produced by ceramic and stainless steel brackets, when combinated with stainless steel wire, during the execution of sliding mechanics. Methods: a simulator and and appropriate methodology were developed. Results and Conclusions: the combination of ceramic bracket with stainless steel wire produced more friction than the stainless steel bracket combinated to stainless steel wire. In conclusion, the execution of sliding mechanics is facilitated when used stainless steel bracket combinated with stainless steel wire.
\end{abstract}

Key words: Friction. Bracket. Wire. 


\section{REFERENCIAS}

1. ANDREASEN, G. F.; QUEVEDO, F. R. Evaluation of friction forces in 0,022" x 0,028" Edgewise bracket "in vitro". J Biomech, New York, v. 3, no. 2, p. 151-160, Mar. 1970.

2. ANGOLKAR, P. V.; KAPILA, S.; DUNCANSON, M. et al. Evaluation of friction between ceramic brackets and orthodontic wires of four alloys. Am J Orthod Dentofacial Orthop, St. Louis, v. 98, no. 6, p. 499-506, Dec. 1990

3. BEDNAR, J. R.; GRUENDEMAN, G. W.; SANDRIK, J. L. et al. A comparative study of frictional forces between orthodontic brackets and arch wires. Am J Orthod Dentofacial Orthop St. Louis, v. 100, no. 6, p. 513-522, Dec. 1991

4. BRUHAT, G.; FOCH, A. Curso de Física geral: Mecânica II. 6. ed. São Paulo: Difusão Européia do Livro, 1964

5. DE FRANCO, D. J.; SPILLER JR., E.; VON FRAUNHOFER, J. A Frictional resistances using teflon-coated ligatures with various bracket-archwire combinations. Angle Orthod, Appleton, v. 65, no. 1, p. 63-72, Jan. 1995.

6. DOWNING, A.; McCABE, J. F.; GORDON, P. H. A study of frictional forces between orthodontic brackets and archwires. $\mathbf{B r} \mathrm{J}$ Orthod, Oxford, v. 21, no. 4, p. 349-357, Nov. 1994.

7. DRESCHER, D.: BOURAVEL, C. SCHUMACHER, H. A. Frictional forces between bracket and arch wire. Am J Orthod Dentofacial Orthop, St. Louis, v. 96, no. 5, p. 397-404, Nov. 1989

8. DRESCHER, D.; BOURAVEL, C.; SCHUMACHER, H. A. Optimization of arch guided tooth movement by the use of uprighting springs. Eur J Orthod, Oxford, v. 12, no. 3, p. 346-353, Aug. 1990.

9. DRESCHER, D.; LAASER, W.; SCHUMACHER, R. A. Materialtechnische untersuchungen zum problem der friktion zwischen bracket undbogen. Fortschr Kieferorthop Munchen, v. 50, no. 4, p. 256-267, Apr. 1989.

10. EDWARDS, G. D.; DAVIES, E. H.; JONES, S. P. The "ex vivo" effect of ligation technique on the static frictional resistance of stainless steel brackets and archwires. Br J Orthod, Oxford v. 22, no. 2, p. 145-153, May 1995

11. BEDNAR, J.R. et al. A comparative study of frictional forces between orthodontic brackets and arch wires. Am J Orthod Dentofacial Orthop, St. Louis, v. 100, no. 6, p. 513-522, Dec. 1991.

12. GHAFARI, J. Problems associated with ceramic brackets suggest limiting use to selected teeth. Angle Orthod, Appleton, v. 62, no. 2, p. 145-152, June 1992.

13. GILL, J. R.: NIKOLAl, R. J. Friction in sliding mechanics: composite orthodontic wires in ceramic brackets. J Dent Res, Washington, D. C., v. 70, p. 483- 1735, Apr. 1991.

14. HALLIDAY, D.; RESNICK, R.; WALKER, J. Fundamentos de Física: Mecânica. 4. ed. Rio de Janeiro: Livros Técnicos e Científicos, 1996

15. HO, K. S.; WEST, V. C. Friction resistance between edgewise brackets and archwires. Aust J Orthod, Melbourne, v. 12, no. 2, p. 95-99, Oct. 1991.

16. HOXIE, M. H.; BEATTY, M. W.; ROBERTSON, B. W. et al. Friction and wear studies of nitrogen-implanted orthodontic wires. J Dent Res, Washington, D. C., v. 75, p. 385, 1996

17. IRELAND, A. J.; SHERRIFF, M.; McDONALD, F. Effect of bracket and wire composition on frictional forces. Eur J Orthod, Oxford, v. 13, no. 4, p. 322-328, Aug. 1991.

18. KEITH, O.; JONES, S. P.; DAVIES, E. H. The influence of bracket material, ligation force and wear on frictional resistance of orthodontic brackets. Br J Orthod, Oxford, v. 20, no. 2, p.109-115, May 1993.

19. KEITH, O.; KUSY, R.; WHITLEY, J. Q. Zirconia brackets: An evaluation of morphologic and coefficients of friction. Am J Orthod Dentofacial Orthop, St. Louis, v. 106, no. 6, p. 605-614, Dec. 1994.

20. KUROE, K.; TAJIRI, T.; NAKAYAMA, T. et al. Friction forces with the friction-free edgewise bracket. J Clin Orthod, Boulder, v. 28 no. 6, p. 347-351, June 1994.

21. KUSY, R. P. Morphology of polycrystalline alumina brackets and its relationship to fracture toughness and strength. Angle Orthod, Appleton, v. 58, no. 3, p. 197-203, July 1988.

22. KUSY, R. P. Commentary: ceramic brackets. Angle Orthod Appleton, v. 61, no. 4, p. 291-292, Dec. 1991.

23. KUSY, R. P.; SAUNDERS, C. R. Surface textures and frictional characteristics of ceramic brackets. J Dent Res, Washington, D. C., v. 70, p. 483, Apr. 1991

24. KUSY, R. P.; WHITLEY, John Q. Effects of surface roughness on the coefficients of friction in model orthodontic systems. J Biomech, Great Britain, v. 23, no. 9, p. 913-925, Sept. 1990.

25. KUSY, R. P.; WHITLEY, John, Q. Coefficients of friction for arch wires in stainless steel and polycrystalline alumina bracket slots. Am J Orthod Dentofacial Orthop, St. Louis, v. 98, no. 4, p. 300-312, Oct. 1990.

26. KUSY, R. P.; WHITLEY, J. Q.; PREWITT, M. J. Comparison of the frictional coefficients for selected archwire-bracket slot combinations in the dry and wet states. Angle Orthod, Appleton, v. 61, no. 4, p. 293-302, Dec. 1991.

27. MARION, J. B. Classical dynamics of particles and systems 2nd ed. New York: Academic Press, 1970.

28. NICOLLS, J. Frictional forces in fixed orthodontic appliances. Dent Pract, Bristol, v. 18, no. 10, p. 362-366, June 1968.

29. OMANA, H. M.; MOORE, R. N.; BAGBY, M. D. Frictional properties of metal and ceramic brackets. J Clin Orthod, Boulder, v. 26, no. 7, p. 425-432, July 1992

30. PALMER, F. Friction. Sci Am, New York, v. 184, p. 55-58, 1951.

31. PETERSON, L.; SPENCER, R.; ANDREASEN, G. A comparison of friction resistance for nitinol and stainless steel wire in edgewise brackets. Quintessence Int, Chicago, v. 13, no. 5, p. 563-571, May 1982.

32. POPLI, K.; PRATTEN, D. H. GERMANE, N et al. Frictional resistance of ceramic and stainless steel orthodontic brackets. J Dent Res, Washington, D. C., v. 68, p. 275, Mar. 1989. Special Issue.

33. PRATTEN, D. H.; POPLI, K.; GERMANE, N. Frictional resistance of ceramic and stainless steel orthodontic brackets. Am J Orthod Dentofacial Orthop, St. Louis, v. 98, no. 5, p. 398-403, Nov. 1990

34. SHIVAPUJA, P. K.; BERGER, J. A comparative study of convencional ligation and self-ligation bracket systems. Am J Orthod Dentofacial Orthop, St. Louis, v. 105, no. 5, p. 472-480, Nov. 1994.

35. SPILLER, R. E. DE FRANCO, D. J. STORY, R J et al. Friction forces in bracket-wire ligature combinations. J Dent Res Washington, D. C., v. 69, p. 155, Mar. 1990

36. STONER, M. M. Force control in clinical practice. Am J Orthod, St. Louis, v. 46, no. 3, p. 163-186, Mar. 1990

37. SYMON, K. R. Mecânica. 3. ed. Rio de Janeiro: Ed. Campus, 1982.

38. TANNE, K.; MATSUBARA, S.; SHIBAGUCHI, T. et al. Wire friction form ceramic brackets during simulated canine retraction. Angle Orthod, Appleton, v. 61, no. 4, p. 285-292, Dec. 1991

39. TSELEPIS, M.; BROCKHURST, P.; WEST, V. C. The dynamic frictional resistance between orthodontic brackets and archwires. Am J Orthod Dentofacial Orthop, St. Louis, v. 106, no. 2, p. 131-138, Aug. 1994

40. VAUGHAN, J. L.; DUNCANSON, M. G.; NANDA, R. S. et al. Relative kinetic frictional forces between sintered stainless steel brackets and orthodontic wires. Am J Orthod Dentofacial Orthop, St. Louis, v. 107, no. 1, p. 20-27, Jan. 1995.

41. YAMAGUCHI, K.: NANDA, R. S.; MORIMOTO, N. et al. A study of force application, amount of retarding force and bracket width in sliding mechanics. Am J Orthod Dentofacial Orthop St. Louis, v. 109 , no. 1, p. 50-56, Jan. 1996

\section{Endereço de correspondência}

Paulo Eduardo Bággio

Rua Pará, 1122 - $2^{\circ}$ andar, sala 24 - Londrina/PR

CEP: 86.010-450

E-mail: pb@sercomtel.com.br 